\title{
UNA GRAN PINTURA MURAL DE LA REAL Y PONTIFICIA UNIVERSIDAD
}

\section{Por Xavier Moyssén}

Hacia 1693 se iniciaron en el antiguo edificio de la Real y Pontificia Universidad de México, una serie de obras tendientes a reparar y ampliar el edificio universitario. Tales obras sólo llegaron a su conclusión sesenta y nueve años más tarde. El tiempo transcurrido no deja de sorprender ciertamente; mas todo encuentra su explicación en una larga lista de razones de muy variada indole y entre ellas la economía fue la de mayor importancia para finalizar los trabajos. Gracias a la energía y empeño que desarrolló durante su largo rectorado, el doctor don Manuel Ignacio Beye de Cisneros, las obras materiales de la Universidad pudieron terminarse conforme a los proyectos presentados por el arquitecto Ildefonso Iniestra Vejarano, proyectos que hicieron del edificio uno de los más notables monumentos barrocos de la capital del virreinato. ${ }^{1}$

Destino adverso fue el que tuvo el edificio de la Real y Pontificia Universidad, mas no es el caso relatar aquí su azarosa historia; sin embargo, para aquellos que quieran informarse de la importancia que tuvo el monumento de Iniestra Vejarano, dentro de la arquitectura mexicana del siglo xviri, varias son las fuentes literarias y los testimonios materiales existentes que dan fe de la grandeza del edificio universitario. Entre las fuentes escritas, acaso la mejor sea la que aparece en la segunda edición de las Constituciones... ${ }^{2}$ La descripción que se hace alli, nos entrega un cuadro detallado de cómo era la Universidad, trece años después de su conclusión. Por otra parte, una mediana idea de la riqueza ornamental que había en la arquitectura del edificio, es la que ofrecen aún las bellas puertas que se salvaron de la furia de la piqueta.

De las obras realizadas por Ildefonso Iniestra Vejarano, quizá ninguna llamó tanto la atención y fue más alabada, que la escalera monumental. La descripción anónima que aparece en la ya citada segunda edición de las Constituciones, al ocuparse de la escalera dice que:

1 Mapa y memorias de la obra que se hizo en esta Real y Pontificia Universidad que presentó el Maestro de ella don Ildefonso Iniestra y Vejarano. Archivo General de la Nación. Universidad, Vol. 525, intitulado: "Obras y Cuentas de los Señores Rectores de esta Real Universidad, de 1730 a $1782 . "$

2 Constituciones de la Real y Pontificia Universidad de México. $2^{*}$ Edición dedicada al Rey nuestro Señor don Carlos III. Fueron extendidas por el Ilmo. Exmo. y Venerable Sr. Dn. Juan de Palafox y Mendoza. México, Imprenta de Felipe de Zúñiga y On. tiveros, 1775 . 
es una de las obras más pulidas y hermosas que ha dado a la luz la Arquitectura en estos Reynos. Su caxa es de trece varas de longitud por nueve y una tercia de latitud. Su entrada son dos arcos, cuyos extremos cargan sobre pilastras de cantería labrada de orden compuesto acosinado y moldeado (sic) uniéndose en el medio, sin columna alguna, que sostenga su proyectura. Se compone de nueve bóbedas planas aristas, con sus masetas, que forman un heptagono simétrico de notable hermosura. Los pasamanos son de hierro de extraordinario artificio, y los pasos o gradas de canteria muy cómodas, que conducen por dos ángulos a desembocar en los corredores altos, por tres arcos labrados de orden compuesto, sobre estípites, que hacen cuatro frentes y revestidos de molduras y talla con los ornamentos correspondientes a tal orden.

La escalera subsistió, tal como ha sido descrita, hasta 1910, año en que el edificio fue parcialmente destruido por orden de la entonces Secretaría de Instrucción Pública; finalmente la estructura de la escalera se desmantelo por completo en 1950, sus canteras labradas se conservan hasta la fecha en la huerta del exconvento dieguino de Churubusco, en espera inútil de que algún día se armen de nueva cuenta. La fotografía de la figura número 8 fue tomada en 1910, cuando la piqueta cumplía su implacable labor.

El cubo de la escalera se convirtió en un sitio de especial importancia, dentro del recinto académico. Así, por ejemplo, el Claustro Universitario, reunido el 21 de junio de 1762, queriendo honrar al rector Beye de Cisneros por el celo que puso para la terminación del edificio y dejar, por tanto, pública constancia de gratitud, dispuso que:

se hiciese un retrato de dicho señor Rector, acompañado de los señores catedráticos actuales, con una imagen de la Purísima Concepción de Nuestra Señora y Santos patronos de esta Universidad y que se pusiera en la escalera, en un hueco principal, con su rótulo en que se exprese, para perpetua memoria, quien había sido el que había hecho esta obra y el año en que se había acabado... 3

Hasta donde nuestras noticias llegan, el cuadro propuesto no llegó a pintarse y sí, en cambio, uno donde aparece retratado únicamente el rector Beye de Cisneros. Este cuadro permaneció poco tiempo en la escalera, pues en noviembre de 1776:

el doctor Francisco Beye de Cisneros preguntó por qué el retrato de su tío el doctor Ignacio Manuel Beye de Cisneros se había quitado de la escalera

3 Alberto Maria Carreño, Efemérides de la Real y Pontificia Universidad de México. Según sus libros de claustros. T. 1t, p. 605. Instituto de Historia, UNAM, México, 1963. 


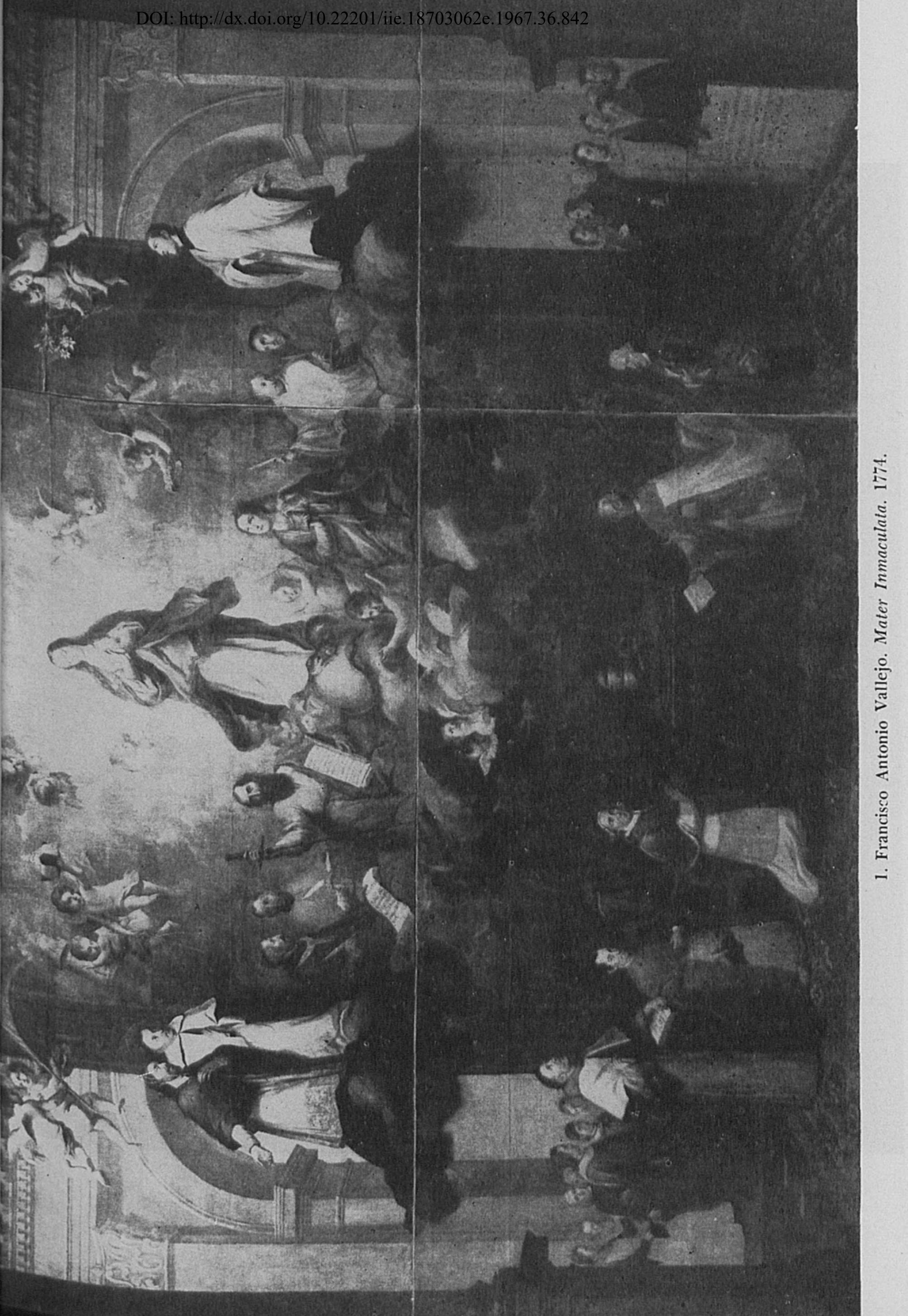




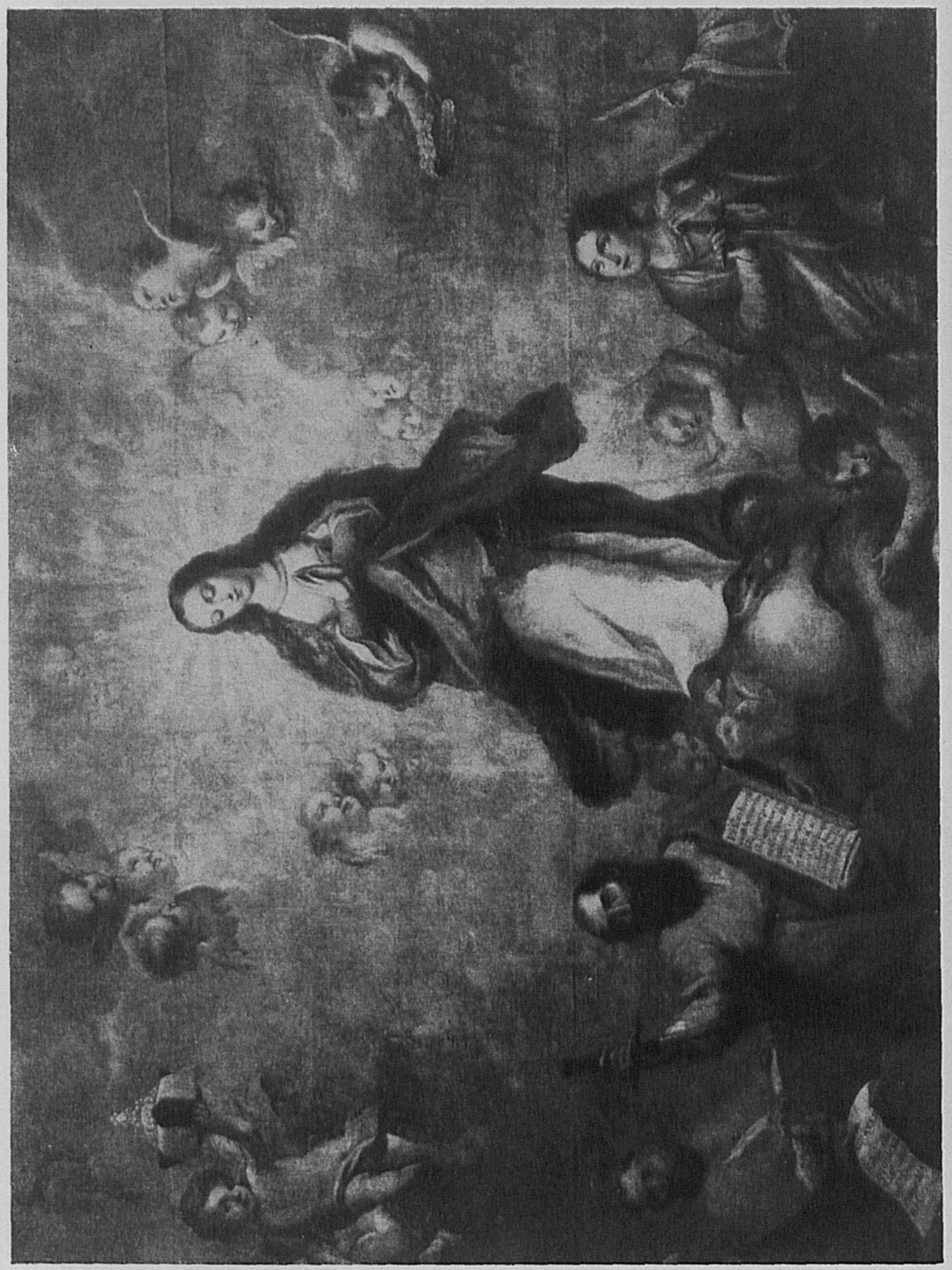




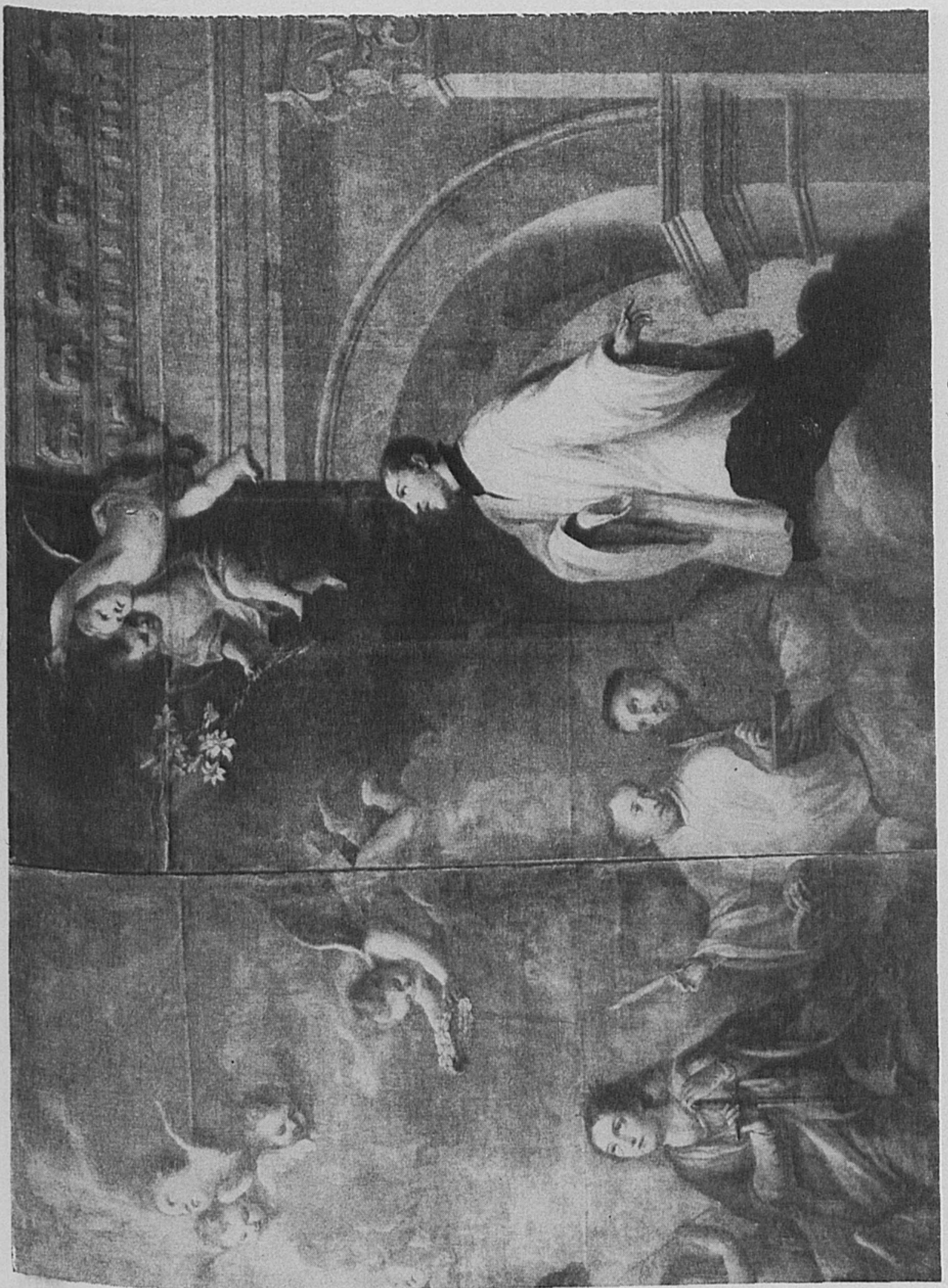


DOI: http://dx.doi.org/10.22201/iie.18703062e.1967.36.842

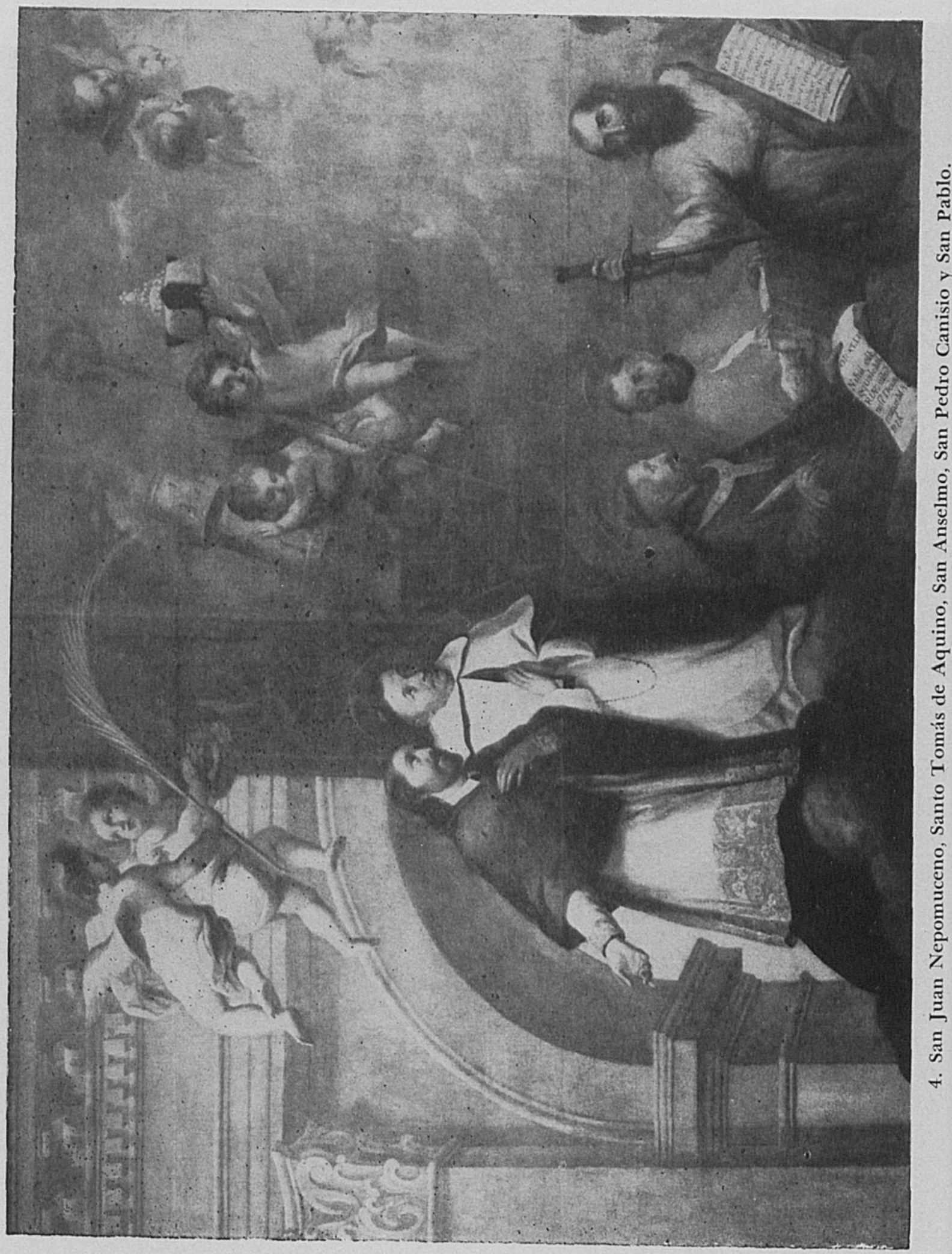


DOI: http://dx.doi.org/10.22201/iie.18703062e.1967.36.842

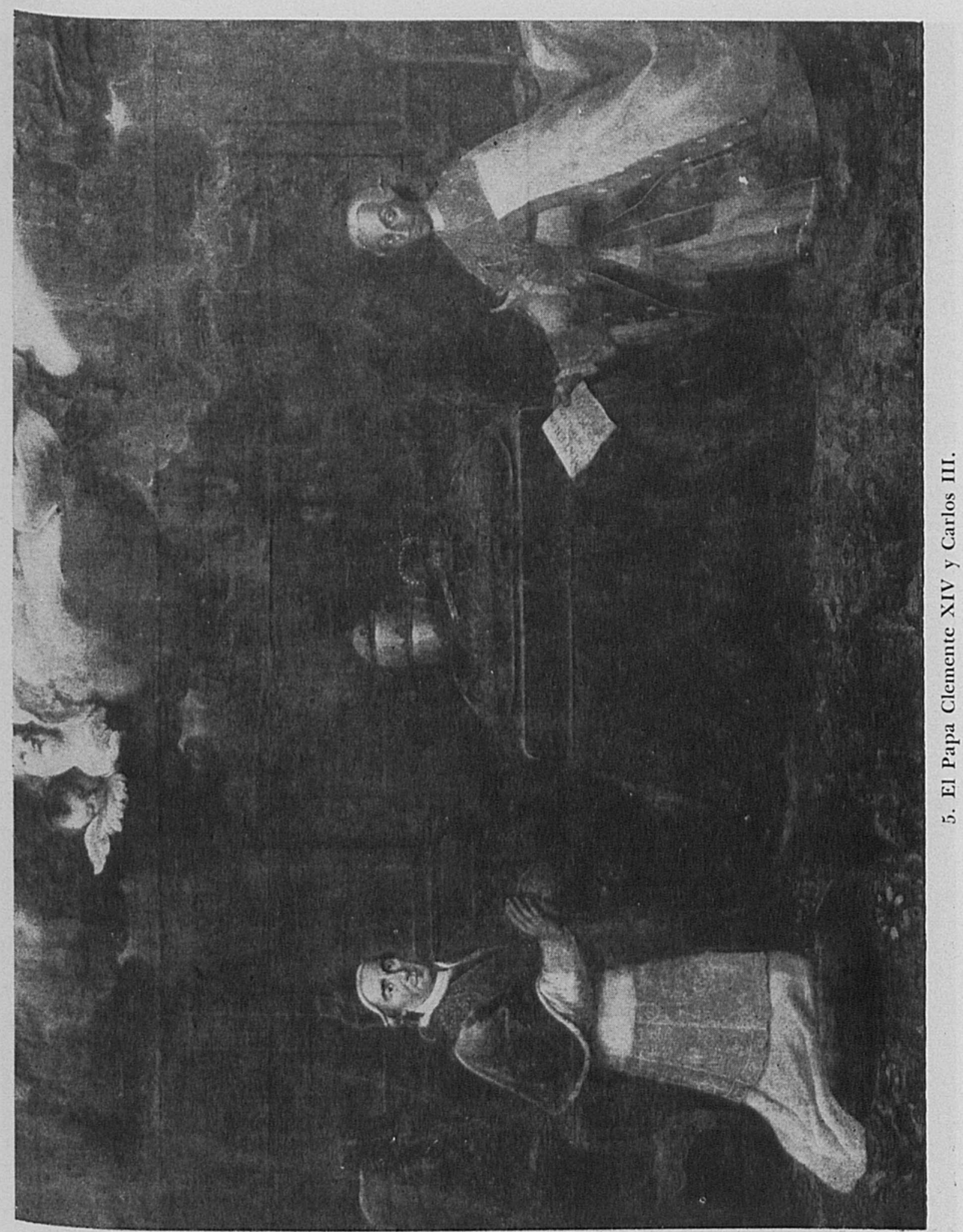




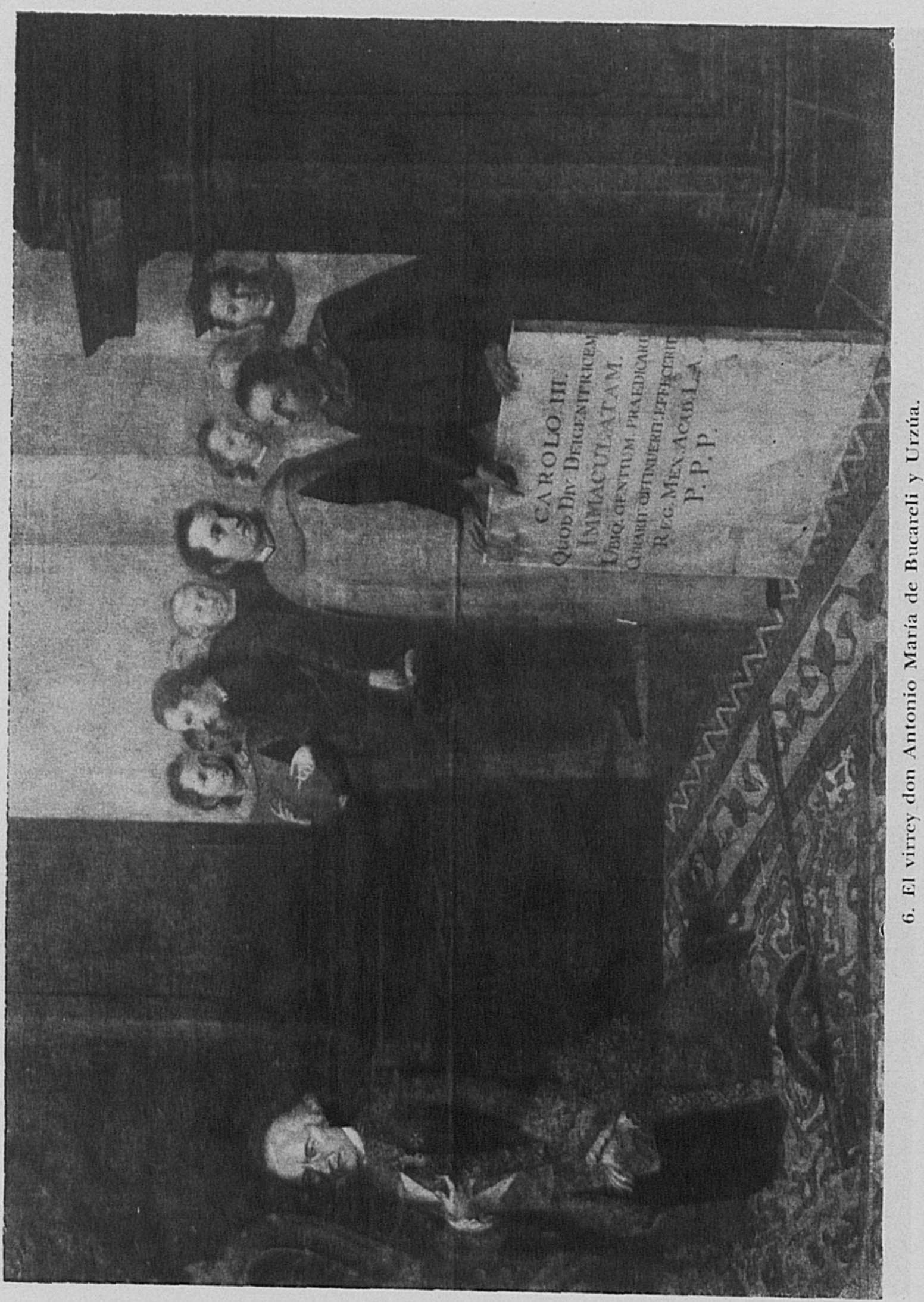


DOI: http://dx.doi.org/10.22201/iie.18703062e.1967.36.842

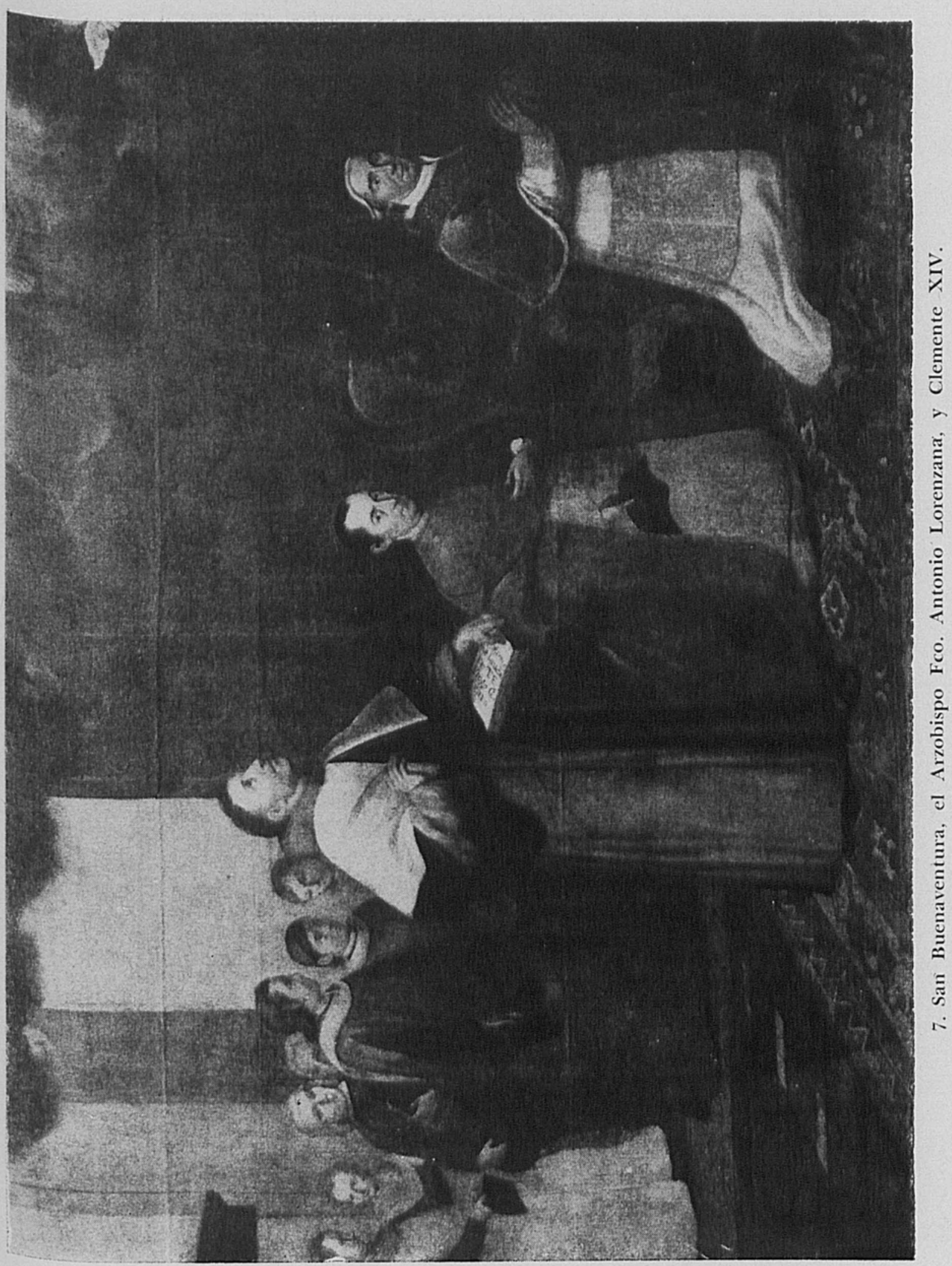




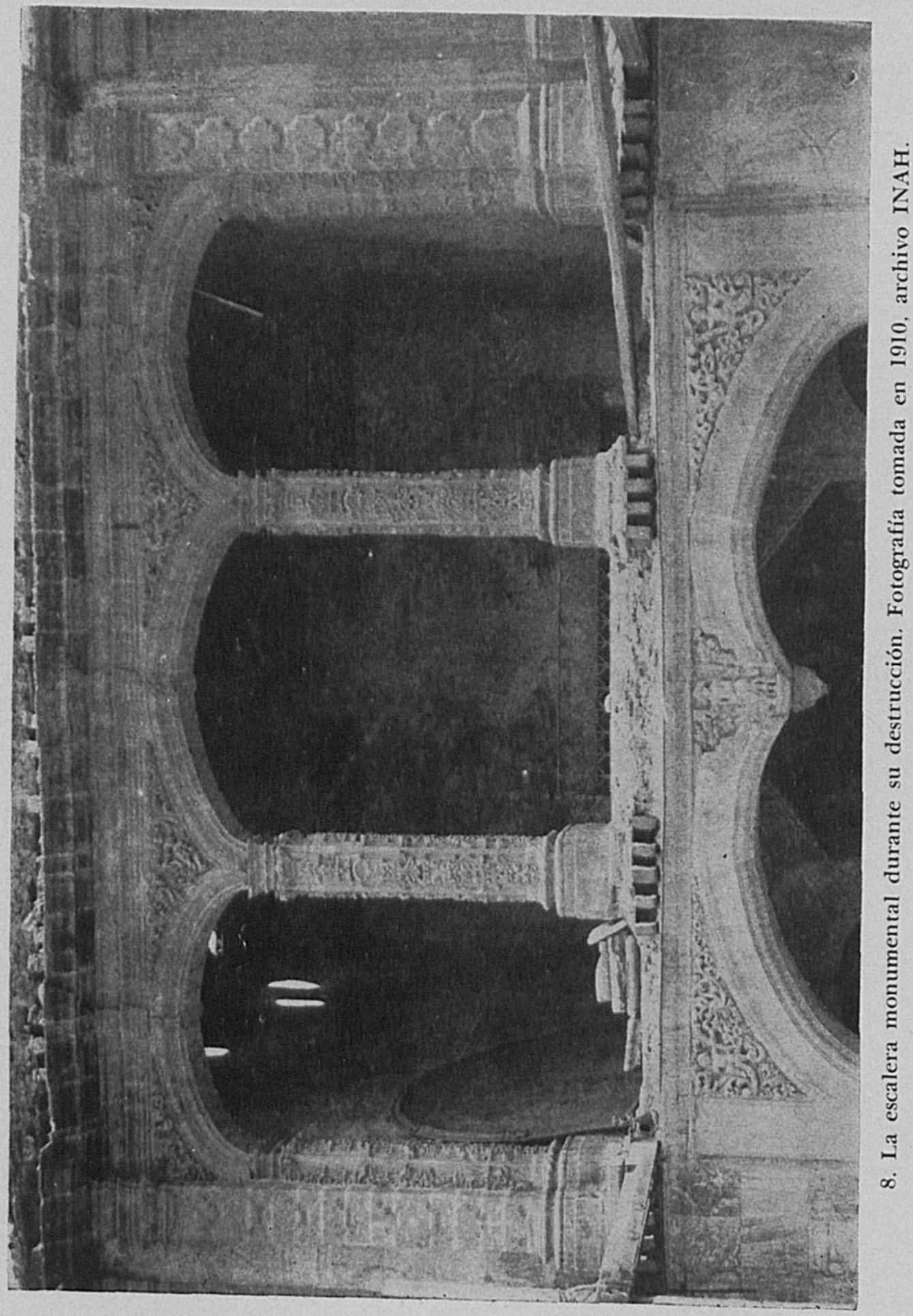


donde estaba y puesto en una de las aulas de menor concurso, a pesar de ser hombre tan benemérito y a quien se debe el restablecimiento de la Escuela en su nuevo planteo y fábrica; por lo cual pasó el Ilustre Claustro a darle las debidas gracias a su casa ... ${ }^{4}$

La razón por la cual el retrato fue removido, adelante habremos de verla; en cuanto a la pintura, encuéntrase ésta actualmente en las colecciones del Museo Nacional del Virreinato en Tepotzotlán.

En los documentos que proceden del antiguo archivo de la Universidad y que hoy día se encuentran en el Archivo General de la Nación, es frecuente que el investigador localice noticias y relaciones referentes a las obras de arte que a lo largo del tiempo la Universidad encargó, con destino a las diversas dependencias que la formaban. Otro tanto cabe decir de las obras impresas que aluden a la importancia que la institución representaba en la sociedad virreinal. Las noticias se refieren a obras escultóricas, imágenes y retablos, a obras de arquitectura y de pintura, aś como de valiosas piezas de orfebrería y finos tejidos.

De las pinturas pertenecientes a la Real y Pontificia Universidad, he logrado localizar un buen número de cuadros, número que es más que suficiente para formarse una idea de la riqueza pictórica que la Universidad poseía. La lista la inicia la pintura de la Purisima, del famoso estandarte atribuido a Hernán Cortés, mismo que fue depositado en el altar mayor de la capilla universitaria, avanzado ya el siglo xvir. En las galerías del Museo Nacional del Virreinato, se encuentran quince grandes retratos de algunas de las eminencias que daban lustre al claustro académico hacia mediados del siglo xvIr, cuadros que estuvieron colocados en el Aula General, según noticia del erudito barroco, don Carlos de Sigüenza y Góngora. ${ }^{5}$ Algunos de estos retratos no son del todo desdeñables y el día que se identifique al anónimo autor (o autores), se hará con ello una buena aportación a la pintura del siglo xvir. En el mismo museo, aparte de otros retratos de rectores y catedráticos, consérvase un gran cuadro, pintado en el siglo xvin, sobre la Conversión de San Pablo, el cual perteneció también a la Institución. En el viejo Paraninfo de la Universidad Nacional, encuéntrase "la colección de doce Sibilas, pintadas en lienzo, pertenecientes a la Biblioteca..." B Ocho retratos más, de

4 Ibid., p. 675.

$5 \mathrm{La}$ noticia se encuentra en su Triunfo Parténico, pp. 244-46, de la edición de 1945, "Ediciones Xóchitl". México.

"Jesús Galindo y Villa, "Apuntes de Epigrafía Mexicana". En Memorias y Revista 
catedráticos y rectores de la Universidad virreinal, están colocados en lo que fue aula mayor de la Facultad de Filosofía y Letras, cuando ésta ocupaba el edificio de "Mascarones". Pero de todas las pinturas que la antigua casa de estudios poseyó, ninguna iguala en importancia al gran cuadro que en 1774 hizo Francisco Antonio Vallejo. Esta obra después de haber pasado un sinfín de infortunios, se conserva debidamente restaurada en la Pinacoteca Virreinal (figura 1).

Tema del presente trabajo es esta última pintura, la cual ocupaba casi por completo el muro central del cubo de la gran escalera edificada por Iniestra Vejarano. Por sus proporciones resulta toda una composición mural, mide en metros: 5.36 de altura por 8.64 de largo.

Cuando reunia el material para escribir su imprescindible Diálogo sobre la historia de la pintura, don José Bernardo Couto estudió el cuadro en su sitio. Y asf, al ocuparse de la obra artística de Francisco Antonio Vallejo, asienta que la pintura que la Universidad le encargó, llevaba como finalidad el conmemorar la gracia que Carlos III había alcanzado del Papa Clemente XIV, para agregar a la Letanía de la Virgen, la deprecación Mater Inmaculata. ${ }^{7}$ Consultados los viejos archivos universitarios, no fue posible localizar el contrato firmado entre la Institución y el artista; tal contrato, de existir, debe detallar prolijamente el tema a desarrollar en el enorme lienzo. Otros documentos relacionados con la pintura, nada dicen respecto a la aseveración de Couto; sin embargo, tanto el tema como las leyendas inscritas en latín en el propio cuadro, dan la razón al ilustre historiador de la pintura virreinal.

La primera de estas leyendas aparece en una gran lápida que es sostenida por jóvenes estudiantes; dice lo siguiente:

CAROLO. III.

QUOD. DIV. DEIGENITRICEM

INMACULATAM.

UBIQ. GENTIUM. PRAEDICARI

CURARIT. OBTINUERIT. EFFECERIT.

REG. MEX. ACAD. L. A.

P. P. P.

Sobre el pedestal de una pilastra colocada a espaldas del virrey Bucareli, se escribió la segunda leyenda: ${ }^{8}$

de la Sociedad Cientifica "Antonio Alzate". Tomo Iv, cuadernos 7 y 8. México, enero y febrero de $189 \mathrm{I}$.

7 P. 102 de la edición con prólogo y notas de Manuel Toussaint. FCE. "Biblioteca Americana". México, 1947.

8 Debo al profesor don Rafael Moreno, las versiones al español; mi agradecimiento 


\author{
D. O. $M$. \\ MATRI VIRGINI IM \\ MACULATAE. MEX. \\ ACAD. DE. SUO. F. P. C. \\ ANNO. A. PARTU. VIR- \\ GINEO. CI. 7. CC. LXXIIII.
}

Mientras no se encuentre el contrato mediante el cual Vallejo trabajó esta enorme pintura, el autor del tema de la misma será el rector Alonso Velázquez Gastellu; tal se desprende al menos, del siguiente documento:

En la Ciudad de México en once de marzo de 1774 dadas las cuatro de la tarde se juntaron en Salas de Claustro de esta Real y Pontificia Universidad con el Sr. Rector de ella Don Alonso Velázquez Gastellu, Sres. Diputados de Hacienda Don Gregorio Pérez Cancino, Don Gregorio Omona, Don Andrés Llanos Valdés, Don Francisco González y don José Girol ... Y también mandaron decir dichos señores que se tape la ventana de la escalera, y se quite por dentro el bordo de cantería que la guarnece y en el claro se ponga un lienzo grande, dejando al arbitrio del Sr. Rector lo que en él se ha de pintar, que les parecía conveniente a dichos Sres. se pintase en él la Purísima Concepción de Nuestra Señora y los Santos Patronos de esta Universidad adorándola, y que se hechasen unos canes fuertes de lienzos (sic) para que lo sostuviesen, y en fin lo dejaban, y dejaron dichos Señores, todo a la sabia y prudente dirección del Sr. Rector, como también el que le destinase lugar en una de las Aulas, a el lienzo que (hoy) en día está en dicha escalera con el retrato del Sr. Don Manuel Ignacio Cisneros. ${ }^{9}$

El lienzo a que se refieren no es otro que el ya citado retrato del rector Beye de Cisneros.

El pago que recibió Francisco Antonio Vallejo por su obra, fue de 600 pesos, los cuales le fueron liquidados en diversas partidas; la fecha de la primera, abril 28, nos indica cuándo el artista principió su trabajo, mismo que finalizó, según el último recibo, el 27 de octubre de ese año, "con lo que quedé enteramente satisfecho de la cantidad concertada", asienta al firmar. ${ }^{10} \mathrm{La}$ pintura resultó tan del agrado del claustro universitario, que no se fijó en gastos con tal de protegerla convenientemente; para lo cual se ordenó al síndico tesorero que

desde aquí. Las leyendas dicen respectivamente: $A$ Carlos III. Porque procuró, obtuvo $e$ hizo que la divina Inmaculada engendradora de Dios, fuese predicada por todas las naciones. La Regia Universidad Mexicana.

Dios Optimo Máximo. A la Madre Virgen Inmaculada. Mexicana Academia. Desde el parto virgineo, año 1774.

O AGN. Universidad, Tomo 33. Claustro de Hacienda 1709-1789. Fol. 181 Vuelta. Gracias a las investigaciones de la señorita Judith Puente, se dan a conocer las noticias de este documento y los que le siguen; me complace manifestarle mi gratitud.

10 AGN. Universidad, Tomo 517. Cuentas del Síndico 1774-1779. 
mandara hacer una cortina de cotense, que cubra los tres arcos de enfrente de la escalera, para que sirva de resguardo a el lienzo que en ella se ha colocado y no se maltrate con el sol. ${ }^{11}$

Entre el grupo de pintores contemporáneos a Miguel Cabrera, figuró con personalidad propia, Francisco Antonio Vallejo. Si respecto a su vida personal sólo escasas noticias son las que se poseen, en cambio su extensa obra atestigua la presencia de un maestro incansable; el que debió gozar de fama y prestigio para que se le encomendaran obras de una magnitud tal como las que ejecutó no sólo para iglesias, escuelas y conventos de la capital, sino aun para sitios tan alejados como San Luis Potosí.

Según Toussaint, Vallejo vio en compañía de Miguel Cabrera y por dos ocasiones, la imagen de la Virgen de Guadalupe, "pero no fue de los elegidos para el examen en 1751". ${ }^{12}$ Sin embargo, Cabrera le pidió su opinión sobre la citada imagen, para incluirla junto con las de José de Ibarra, Manuel de Ossorio, Juan Patricio Morlete Ruiz, José de Alcibar y José Ventura Arnáez, en su Maravilla americana. Otras noticias referentes a Vallejo, indican que éste figuró entre los artistas que en 1754 se reunieron en torno al decano de los pintores, que entonces lo era José de Ibarra, para fundar aquí una Academia de Pintura, semejante a la recién fundada de San Fernando de Madrid. Tal parece que el destino había señalado a Francisco Antonio Vallejo, para que impartiera sus conocimientos en una academia; si respecto a la que se trató de establecer en 1754 , no hay mayores noticias, ${ }^{13}$ lo cierto es que Vallejo aparece de nueva cuenta como profesor de pintura en 1784, en la recién inaugurada Academia de San Carlos, según Manuel Revilla. ${ }^{14}$

-La extensa obra de Francisco Antonio Vallejo, corresponde cabalmente al último periodo del gran barroco mexicano, las enormes composiciones que trabajó, llenas de una retórica teatral no exenta de superficialidad, le acusan como a un pintor sujeto a los dictados estéticos del periodo señalado. No obstante, su personalidad artística aparece bien definida en los colores que manejó en su paleta, sobre todo en el azul, el cual llega a ser una invariante que mucho ayuda a identificar los cuadros salidos

11 Ibid.

12 Manuel Toussaint, Pintura colonial en México, p. 168. Instituto de Investigaciones Estéticas. UNAM. México, 1965.

13 Xavier Moyssén. "La Primera Academia de Pintura en México". En Anales del Instituto de Investigaciones Estéticas. Vol. IX, núm. 34. pp. 15-29. México, 1965.

14 Manuel G. Revilla. El arte en México, p. 144. México, 1923. 
de su taller; el color azul aparece siempre en diversas gamas, dentro de la composición cromática total. Como dibujante, Vallejo es de una calidad inferior; débil y descuidado, muéstrase en repetidas ocasiones, a pesar de que el asunto lo ha tomado indudablemente de una lámina.

Es hacia la octava década del siglo xvil, cuando apareció en el arte de la Nueva España, el gusto por la pintura al óleo y sobre tela, para cubrir grandes superficies en iglesias, conventos y hospitales. En cierta forma con esto vino a suplirse el empleo de la pintura mural que cayó en desuso por la limitación de sus valores expresivos, insuficientes para cubrir las exigencias del arte barroco, amante de composiciones violentas de luz y color, que las viejas técnicas del temple o el fresco, no podían ofrecerle. El empleo de estas grandes composiciones murales, a pesar de no estar trabajadas directamente sobre los muros, alcanzó una enorme difusión en el siglo xvir.

La enorme tela que Francisco Antonio Vallejo pintó en 1774 para la Universidad, está concebida en un ambicioso plan escenográfico; la obra se presenta a los ojos del espectador, como un magnífico espectáculo que le incita a la observación de cuanto acontece dentro de sus propios limites. A ese carácter escenográfico contribuye ventajosamente, el fondo de arquitectura monumental que lleva.

Lo primero que sorprende cuando se estudia el cuadro, es la estructura de su composición, pues está trazada con un cierto equilibrio que no corresponde por completo al arte barroco de la época. No se quiere decir, con esto, que Vallejo haya renunciado a los medios de composición que le ofrecía el barroco, no, más bien, creemos que él los subordinó hábilmente a un orden de equilibrio y de calma. La composición obedece, en rigor, a dos razones; la primera es de carácter religioso y simbólico, en tanto que la segunda lo es puramente de orden estético.

En la composición estética la estructura queda indicada a través de varios ejes verticales, para los cuales se han aprovechado las formas severas de la arquitectura clásica. Un eje ideal señala la mitad de la composición con la figura de la Purísima. En concordancia con este centro, se ha trazado una estructura triangular de enorme importancia, como habrá de verse más adelante. En la base del triángulo están colocadas las manos de los personajes que aparecen hincados y la cúspide encuentra su correspondencia, justo en las manos de la Virgen. La rigidez de las líneas rectas que hay en la composición, se rompe gracias a las suaves li- 
neas de dos grandes curvas que parten de derecha a izquierda o viceversa, desde los extremos de la parte superior. De más está decir que a estas curvas les inflaman movimiento las diversas formas que hay en su trayecto.

La estructura señalada no le fue dada a la pintura de manera aislada al tema que contiene. Todo lo contrario, está en relación estrecha con la composición simbólica del propio tema; así, por ejemplo, esas dos curvas ideales que se han indicado, sirven de división a los dos mundos que la pintura en sí, representa. El eje central de que se ha hablado lleva en la parte superior la imagen de la Purisima, en tanto que en la parte inferior aparecen los emblemas del poder terrenal: la tiara papal, más el centro y la corona de la monarquía; queda así indicada la jerarquía del mundo supraterreno sobre el terrestre. Obedeciendo a este orden de valores, fue por ello que en el centro de la composición se dispuso la estructura triangular ya referida; las manos colocadas en la base, corresponden a los representantes del poder terrenal: el papado y la monarquía, en tanto que las manos de la Virgen indican el poder celeste; con lo cual, como se ve, se enfatiza nuevamente la jerarquía de lo divino sobre lo humano. Por otra parte, dentro del triángulo sólo han tenido cabida Clemente XIV y Carlos III, subrayándose así otro orden de valores: ellos son los representantes directos y absolutos de la divinidad, sobre el resto de los mortales.

Si se atiende al tiempo empleado por Vallejo en la factura del cuadro, seis meses, en las dimensiones del mismo, así como en la calidad poco uniforme de sus valores plásticos, se comprende con ello que debió trabajarlo en su obrador y con el concurso o ayuda de sus oficiales; no hay que olvidar, además, que en el mismo año salieron de sus manos otras obras de regular tamaño. Que esta pintura de la Universidad no se debe únicamente a él, lo indica con claridad la desigualdad que hay en el dibujo y en la pincelada misma de ciertas áreas; como ejemplo de lo dicho, pueden verse las cuatro figuras de los doctores marianos. La falta de uniformidad señalada, es falla común en la pintura de la época, pues ante la apremiante demanda de telas que los artistas tenían, sólo dieron cantidad y excepcionalmente calidad. $Y$ sin embargo, es conveniente formularse la siguiente pregunta: ¿hasta qué punto este vicio de la pintura novo-española del siglo xvin, es adjudicable únicamente a los artistas? Quizá antes de condenarles convenga reflexionar también, sobre el gusto estético que tenfan aquellos que les encargaban las obras y lo que esperaban o exigían de las mismas.

Conforme al tema central del cuadro, la imagen de la Purísima lo pre- 
side todo. Vallejo representó a la Virgen, apegado a la iconografía tradicional; un rompimiento de gloria le sirve de fondo, está de pie sobre la sierpe que muerde la manzana mientras se enrosca en el mundo; no faltan otros símbolos como los angelillos y querubes, las estrellas y los colores de las vestiduras: blanco el traje y azul el manto que le envuelve con un suave vuelo. Apegado a la tradición del dogma. Vallejo en la parte más afortunada de su inspiración ha interpretado a la Purísima, como una mujer joven, casi adolescente, de delicadas y bellas facciones. La imagen es la mejor lograda de todas las que componen el gran cuadro. El tratamiento que hay en ella, tanto en lo ideal como en lo puramente pictórico, califica a su autor como a un maestro con personalidad propia entre sus contemporáneos. No es aventurado afirmar que esta Virgen es una de las más bellas que dio la pintura mexicana del siglo xvirI (figura 2).

En un plano inferior y a los lados de la imagen de la Purísima, se encuentran los santos tutelares de la Real y Pontificia Universidad, Santa Catalina y San Pablo, portando sus atributos simbólicos. San Pablo tenía una singular importancia dentro de la Institución, pues ésta se fundó precisamente en una fecha que coincidía con la conversión del santo: 24 de enero de 1553. A continuación Vallejo dispuso las figuras de cuatro de los doctores marianos: San Bernardo y San Ildefonso, aparecen en el lado derecho, en tanto que San Anselmo y San Pedro Canisio, lo están en el izquierdo. El pintor se preocupó por dar una cierta vida a los doctores; en el diálogo que éstos sostienen parecen comentar sus propios escritos sobre la pureza de Maria. Por desgracia las figuras son débiles tanto en el dibujo como en el colorido (figuras 3 y 4 ).

El joven jesuita San Luis "Gonzaga, fue escogido para patrón de los es. tudiantes, su juventud misma era el símbolo apropiado. Vallejo lo colocó en el extremo derecho, postrado y lleno de devota admiración hacia la Virgen; sobre su cabeza un par de juguetones angelillos, portan un ramo de azucenas, con lo que se puntualiza la pureza de su vida (figura 3). En el lado opuesto y guardando la simetría de la composición, se encuentran en actitud contemplativa dos de los patrones principales de los estudios: San Juan Nepomuceno y Santo Tomás de Aquino; este último, además del tutelaje que tenía sobre los estudios filosóficos, figura entre los principales defensores del dogma mariano (figura 4).

Descrito el plano celestial en la forma que se ha visto, ocupémonos del inferior o mundano para ver cómo lo resolvió Vallejo. Pero antes de continuar anotemos que con un recurso que la pintura barroca utilizó sin moderación ni mayor originalidad, el artista mexicano separó ambos planos mediante un grupo de agitadas nubes. 
Guardando el orden y la armonía de la composición del enorme lienzo, en la parte central aparecen de hinojos el papa Clemente XIV y el rey Carlos III; atrás de ellos se dejan ver sus respectivos tronos y sobre una mesa cubierta, dispuesta en el centro, están la triple corona papal, así como el cetro y la regia corona española. El rey porta en la diestra un pergamino en el que se lee la deprecación Mater Inmaculata. Ora pronobis, misma que sirvió de tema, como se ha visto, para que se hiciera esta pintura. Para trabajar Francisco Antonio Vallejo los retratos de Clemente XIV y Carlos III, se valió de grabados que eran de uso común entre los artistas del reino. Las láminas que se grabaron del conocido retrato que Mengs pintó al monarca, fueron numerosas y gracias a ellas los maestros americanos consiguieron llevarlo a sus lienzos con más o menos fidelidad. La copia de una lámina del grabador Francisco Vaden, permitió a Vallejo pintar el retrato del pontífice, retrato que es de una calidad que no se encuentra en el del rey; tiene una vida y una hondura de carácter, hábilmente conseguidas. La devoción de Carlos III al dogma de la Purísima Concepción, alcanzó con esta enorme tela su máxima manifestación; pero en ella Vallejo nos ha entregado la imagen de un rey casi anciano, decrépito; diríase que al artista le faltó emoción y aun simpatía para pintarlo. Por lo demás, Carlos III aparece ricamente engalanado con el hábito de la orden por él fundada.

Los representantes en la Nueva España, tanto del papa como del rey, lo eran en esta época el arzobispo don Francisco Antonio Lorenzana y el virrey don Antonio Maria de Bucareli y Urzúa; ambos personajes fueron incluidos en el tema de la pintura; tal como correspondía a su jerarquía aparecen hincados, atrás de Carlos III y Clemente XIV. Es aventurado precisar hasta qué punto esta obra se debe a la inspiración artística de Vallejo. De otros cuadros suyos se ha comprobado que la composición o figuras de los mismos, se deben por completo o parcialmente a la copia de grabados europeos; pero asimismo hay muchas telas que se deben únicamente a la originalidad e inventiva de su propio talento estético. Respecto a esta pintura de la Real y Pontificia Universidad, se ha visto que el tema de la misma salió de los componentes del propio claustro universitario; sin embargo, cabe preguntar chasta dónde se apegó Vallejo a las indicaciones que le hicieron, para inventar la composición? Dejemos ese problema pendiente para ocuparnos tanto del virrey como del arzobispo, los únicos personajes vivos, reales, que el artista tuvo a la vista (figuras 6 y 7). Es muy posible que para retratarlos se hayan prestado a posar, hay en ellos la naturalidad que se encuentra en los retratos tomados directamente. El de Bucareli muestra a éste, con esa sobriedad de 
carácter y de presencia que habla en él, según las noticias existentes. En cuanto a don Francisco Antonio de Lorenzana, Vallejo nos ofrece una magnifica imagen de uno de los personajes más inquietos e interesantes de la vida religiosa y cultural del México de mediados del siglo xvir; talento, bondad y simpatía se encuentra en la amplia frente, en los grandes ojos y en la velada sonrisa del arzobispo. Su retrato, como obra de arte, es superior desde luego al del virrey.

La sección inferior o mundana de la pintura, se cierra con los grupos de jóvenes estudiantes que aparecen en los extremos; visten diversos trajes o "brecas", según los colegios a que estaban incorporados; desgraciadamente no se trata de retratos reales de los estudiantes; son figuras insipidas e impersonales, ayunas de toda vida interior y del carácter que siempre ha distinguido a los colegiales.

Para establecer un enlace, una relación entre el mundo ideal del cielo y el de los hombres, en la composición simbólica se dispuso que al lado del arzobispo Lorenzana, estuviera nada menos que uno de los grandes defensores del dogma mariano: San Buenaventura. Está el santo franciscano de pie, viste el hábito de la Orden Seráfica, pero porta, además, la doble muceta que ha ganado con la sabiduría de su prédica y escritos. Su figura es bella y noble, en la diestra porta la pluma, en tanto que la otra mano sostiene con energía el grueso libro donde escribe las verdades de su revelación. La cabeza de Buenaventura, vuelta hacia lo alto, recibe directamente la inspiración del portento que tiene a la vista. En la pintura religiosa, como sucede con todo arte, no hay imposibles, de alli que no resulte del todo insólita, la presencia del santo franciscano entre los mortales (figura 7).

En la historia de la pintura mexicana de la segunda mitad del siglo xviII, un lugar de primera consideración merece esta obra de Francisco Antonio Vallejo; tanto por la originalidad del tema desarrollado, con indudable fortuna, como por los valores artísticos que encierra. Acometer obras de las dimensiones de esta tela, es buena prueba para todo artista; Vallejo salió avante. El cuadro, visto al lado de otras obras de la época, destaca por sus valores propios, sale de lo común.

La Real y Pontificia Universidad de México, al encargar la realización de esta pintura, dejó el testimonio artístico de una de las grandes fuerzas espirituales que movían a la sociedad a que se debia: el dogma de la pureza de María. 